\title{
CORPUS Corpus
}

Archivos virtuales de la alteridad americana

Vol 2, No $1 \mid 2012$

Enero / Junio 2012

\section{El Museo Histórico Regional“Emma Nozzi” de Carmen de Patagones}

The Regional Historical Museum "Emma Nozzi" of Carmen de Patagones

Jorge A. Bustos, and Leonardo A. Dam

\section{OpenEdition}

\section{Journals}

Electronic version

URL: http://journals.openedition.org/corpusarchivos/993

DOI: 10.4000/corpusarchivos.993

ISSN: 1853-8037

\section{Publisher}

Diego Escolar

Electronic reference

Jorge A. Bustos, y Leonardo A. Dam, "El Museo Histórico Regional“Emma Nozzi” de Carmen de Patagones », Corpus [En línea], Vol 2, No 1 | 2012, Publicado el 30 junio 2012, consultado el 19 abril 2019. URL : http://journals.openedition.org/corpusarchivos/993; DOI : 10.4000/corpusarchivos.993

This text was automatically generated on 19 April 2019

Licencia Creative Commons: Atribución-NoComercial 2.5 Argentina (CC BY-NC 2.5 AR) 


\section{El Museo Histórico Regional“Emma Nozzi” de Carmen de Patagones}

The Regional Historical Museum "Emma Nozzi" of Carmen de Patagones

Jorge A. Bustos, and Leonardo A. Dam

\section{EDITOR'S NOTE}

Fecha de recepción del original: 15/05/2012. Fecha de aceptación para publicación:

$18 / 06 / 2012$

1 El museo está situado en una de las esquinas de mayor densidad histórica de la Patagonia. En Carmen de Patagones, a orillas del río Negro frente a los muelles, en la calle de los boliches, almacenes y barracas que fueron transitados desde los tiempos fundacionales. Allí nos desempeñamos los historiadores, museólogos, técnicos y colaboradores. Pero antes que nosotros, por nuestra esquina podían ser vistos Francisco de Viedma, las sufridas familias de inmigrantes peninsulares, los presos deportados, los rudos loberos y balleneros de los mares australes, los corsarios de la guerra con el Brasil, los esclavos africanos, el naturalista francés Alcide D'Orbigny, el marino Piedra Buena, los caciques Llanquitruz, Casimiro Biguá, Foyel y Orkeke, el explorador inglés Musters, el lazarista Savino, las tropas de Roca y el mismo Julio Argentino Roca, los misioneros Espinoza, Fagnano y Cagliero; y bajando desde la colina del Fuerte, las columnas de guerreros vencidos, los ancianos, mujeres y niños mapuches, pampas y tehuelches a quienes se embarcaba desde el muelle para ser trasladados a la isla Martín García en Buenos Aires, la que oficiaba de cuartel militar, presidio y campo de concentración de indígenas. Esos antiguos pasos, gritos, risas, gemidos e imprecaciones hacen eco en los muros de las salas del museo y se vuelven murmullos de historias que se cuentan en los papeles de nuestro archivo. Procuramos que todas ellas cobren forma en los relatos de los guías, en nuestras indagaciones y en las de los investigadores que nos visitan. 


\section{Historia del museo y sus edificios}

2 El Museo Histórico Regional "Emma Nozzi" es actualmente un organismo del Banco de la Provincia de Buenos Aires. Fue creado en 1951 con el nombre de "Francisco de Viedma", el fundador del fuerte y población Nuestra Señora del Carmen. Al año siguiente pasó a depender de la municipalidad de Patagones y a funcionar en la planta baja de la sede comunal. En 1988 el museo con todo su patrimonio y personal fue traspasado al Banco de la Provincia de Buenos Aires y, desde entonces, funciona en su sede actual. En 1991 cambió su nombre por el de "Emma Nozzi"; Emmita, como todos la llamábamos, fue su directora durante más de cuatro décadas, consagrando su inteligencia, sueños y energía al sostenimiento del patrimonio cultural tangible e intangible de los "maragatos", tal como se conoce a los pobladores de Carmen de Patagones. La institución posee un acervo edilicio, museológico y documental cuyo valor merece ser destacado.

3 Los tres inmuebles que integran el patrimonio edilicio del museo, la "Casa Histórica del Banco de la Provincia en Carmen de Patagones", la "Casa Cagliero" y la casa histórica "La Carlota" detentan la condición de Monumento Histórico Nacional y se encuentran emplazados en el viejo barrio del puerto que a su vez ha sido declarado Poblado Histórico Nacional. La Casa del Banco se levanta en uno de los primeros solares ocupados por dependencias coloniales desde 1779. Entre 1884 y 1894 funcionó como local de la primera sucursal del Banco. Antes, entre 1855 y 1875 había alojado a la empresa "Aguirre y Murga" que influyó poderosamente en el desarrollo de la economía regional con un saladero que llegó a ser considerado, por su volumen de producción y cantidad de trabajadores que ocupaba, como "...la vida de este Partido".

4 En 1877 la casa fue adquirida por el lazarista José Savino como sede de la misión y del proyectado Colegio Santa María de las Indias. A partir de 1880 alojó a José Fagnano y sus salesianos, orden que relevó a los lazaristas en la conquista evangélica de la Patagonia. Desde 1895 y hasta la pavorosa inundación de 1899 fue sede de la primera sucursal del Banco de la Nación Argentina en la Patagonia. El patio del edificio alberga una cueva labrada por los pioneros en las barrancas del río. Las dependencias internas contienen, en un ala, las salas de exposición y en la otra, la administración, la biblioteca y el archivo histórico.

5 La Casa Cagliero, aledaña a la anterior, también adquirida por Savino y cedida a los salesianos, fue la primera sede del Vicariato Apostólico de la Patagonia, siendo la residencia del propio Juan Cagliero. Contiene la reserva museológica y una espaciosa sala de usos múltiples. Dos proyectos de próxima realización son la instalación de un bar temático y la ampliación del archivo, biblioteca y la reserva museológica. A partir de la reforma, restauración y puesta en valor que realizó el Banco Provincia en 2009, este inmueble se comunica interiormente con el lindero. Ambos se inscriben dentro del estilo italianizante que predomina en el casco histórico de Carmen de Patagones.

La Casa Histórica La Carlota, a dos cuadras de las anteriores, subiendo la calle que conducía al Fuerte, es en cambio un típico rancho del estilo de las primeras construcciones de la colonia. Fue levantada hacia 1820 en un período de auge de la ganadería, la explotación salinera y la extensión del área de cultivos, todo ello en el marco de la intensificación de los intercambios económicos y los acuerdos políticos con las jefaturas pampas y tehuelches. El interior posee un dormitorio, una cocina y una 
salita, ambientados con muebles y utensilios que en su mayor parte corresponden a la segunda mitad del siglo XIX.

\section{Patrimonio museológico y documental}

7 El grueso de nuestro patrimonio museológico está compuesto por objetos que permiten dar cuenta de distintos aspectos de la vida cotidiana, urbana y rural del siglo XIX y la primera mitad del XX. En nuestras salas los objetos sustentan un guion museológico que narra la historia de la región, organizada en cinco etapas. Las tres primeras conforman el núcleo del recorrido que se ofrece a los visitantes, lo que se explica por el interés que despierta la condición de Carmen de Patagones como sociedad de frontera. Más precisamente se trata de la etapa pionera que transcurre entre 1779 y 1820 en que el establecimiento va de la condición de enclave estratégico de la geopolítica hispana a las críticas condiciones post independencia que la pusieron al borde de su desaparición. Un segundo momento llega hasta fines de la década de 1850 con la sal destinada a los saladeros rioplatenses como fuerte protagonista del sostenimiento de la población. Dentro de este período el combate de 1827 contra una invasión del Imperio del Brasil constituye un hito para la identidad histórica local, a partir del protagonismo que el pueblo en armas tuvo durante el mismo, lo que se expresa significativamente en el relato museológico. La tercera etapa a que nos referimos, se abre con el tratado de paz con el cacique Yanquitruz de 1857 que asegura una instancia de especial articulación social, política y militar que se continuó con sus sucesores Chingoleo y Linares, hasta la campaña de 1879.

8 Además de los objetos de vida cotidiana el relato museológico se apoya en una serie de piezas singulares. Por caso una silla de fumar que perteneció al corsario Fourmantin; una cómoda del corsario Harris que concluyó en su descendiente Liborio Justo; objetos de la corbeta brasileña Itaparica; instrumentos náuticos que pertenecieran al marino Luis Piedra Buena, nacido a escasos metros de la sede del museo... Este acervo contribuye a materializar esta historia política que también se encuentra condensada en las pertenencias de los comandantes del fuerte Francisco Fourmatin y Liborio Bernal de las décadas de 1840 y 1870 respectivamente, un cigarro de los que gustaba fumar el coronel Villegas, la platería mapuche y tehuelche o el estoque de un liberto con las incisiones en su hoja recordando a cada rival herido o muerto en duelo. La ampliación del museo a partir de la incorporación a la muestra de la "Casa Cagliero" permitirá un mayor desarrollo sobre la historia de la primera mitad del siglo XX. Lo político se referencia actualmente en fusiles de la revolución radical de 1893 y elementos ceremoniales de la logia local Torcuato Taso que incluyen las columnas del templo y notables fotografías. La colonización agraria, hacia el interior del Partido de Patagones, en tanto, se apoya, además de fotografías, en una pechera de caballo de los colonos alemanes del Volga y una rueda metálica de tractor de la década de 1920 . Hemos creado un espacio de memoria oral "Me acuerdo y te cuento" con un capítulo urbano y otro rural que aleatoriamente nos permitirá incrementar los objetos de nuestra campaña cuyo tamaño permita su instalación en las salas.

El espesor de la memoria histórica se sostiene además en los valiosos fondos documentales provenientes de diversos organismos públicos locales: la Municipalidad, el Juzgado de Paz, la Aduana, la comandancia del Fuerte, el Concejo Escolar. A continuación, un somero detalle del contenido de aquellos que se preservan en nuestro museo: 


\section{Archivo Histórico de la Municipalidad de Patagones} cuando se constituye la Municipalidad de Carmen de Patagones, que concluye en 1973. La jurisdicción de la provincia de Buenos Aires y por ende del municipio incluáa la banda sur del río Negro hasta la formación del Territorio Nacional de la Patagonia en 1878, por lo que el fondo contiene la documentación concerniente a la población sureña que daría origen a la ciudad de Viedma.

11 El material se divide en dos áreas: Departamento Ejecutivo y Concejo Deliberante (HCD). Los cuerpos documentales más completos son los referidos a tierras urbanas y rurales y los libros de actas de sesiones del HCD. De cualquier modo, la sección de copias de notas del Departamento Ejecutivo que estamos organizando actualmente es muy valiosa a pesar de su fragmentación.

Quizás lo atinente al siglo XIX resulte más relevante para investigadores foráneos dada la condición de sociedad de frontera que revestía Carmen de Patagones y su entorno. La documentación puede abonar entonces, investigaciones planteadas en pos de variables espaciales más amplias. Recientemente hemos incorporado a este repositorio los registros de la Defensoría de Menores de Carmen de Patagones que abarcan los años entre 1835 y 1949.

\section{Aduana de Carmen de Patagones}

Esta sección que contiene documentación datada entre 1909 y 1964 se encuentra en proceso de organización. La tarea es ardua ya que cuando el material fue recogido, era apenas una masa informe de papeles. No hemos esclarecido aún la cuestión jurisdiccional, pero según tenemos visto, además de la Aduana del Puerto de Patagones, el archivo contiene documentación sobre los Resguardos - unidades administrativas dependientesde los puertos de San Blas y San Antonio Oeste. Entonces, se cuenta aquí con documentación sobre embarques de mercaderías recibidas y enviadas desde los puertos de la jurisdicción, copiadores de la empresa naviera Mihanovich $\mathrm{y}$, en general, información de distinto orden sobre importadores, exportadores, marítimos, buques y remolcadores que operaban en los tres puertos citados.

\section{Comandancia Militar de Patagones}

Se trata de tres libros copiadores de notas. El primero corresponde al período 1781-1795. Los dos siguientes comprenden desde 1874 hasta 1879. El copiador colonial contiene notas sobre cuestiones administrativas referidas a los establecimientos del río Negro y San José en península Valdés, remitidas por los sucesivos comandantes del establecimiento a las autoridades virreinales. Los otros dos copiadores coinciden en el tiempo con la comandancia de Liborio Bernal y fueron ingresados al patrimonio del museo gracias a la donación de su nieto, Liborio Justo. La mayoría de las notas está dirigida al ministro de Guerra y Marina, al Inspector General de Armas y al sargento Mayor Linares heredero del poder de Sayhueque y de su hermano Chingoleo, al frente del Batallón de Indios Amigos que estaba subordinado a la comandancia. Las notas versan sobre una diversidad de temas 
atinentes a las relaciones con las tribus, a la administración de los recursos, a la logística militar y a las relaciones con los poderes locales. En general la correspondencia da cuenta de las complejas responsabilidades del comandante que debía sostener un rol de autoridad que evidenciara a la vez energía, decisión y una gran capacidad de articulación de un universo de actores sobre los que ejerce una preeminencia que es puesta a prueba cotidianamente.

\section{Archivo del Juzgado de Paz de Patagones}

Este repositorio contiene documentación desde 1835 hasta 1926 en materia civil, comercial y penal. Sobre las dos primeras materias pueden encontrarse, entre otros, los siguientes temas: disposiciones sobre la caza de nutrias y avestruces, sobre el arrendamiento de terrenos públicos, permisos de embarque y desembarco, testamentarias, disposiciones sobre el enrolamiento de guardias nacionales, solicitud de estancias en propiedad, litigios por propiedad de tierras, demandas por "cobros de pesos". En cuanto a lo penal se encuentran expedientes sobre pedidos de captura, comunicaciones sobre los reos confinados a Carmen de Patagones, agresión a mano armada, homicidio, lesiones, robo, alteración del orden, cuatrerismo, uso del cintillo punzó, sevicia, injurias, fuga del hogar, atentado a la honestidad, etc.

\section{Hemeroteca}

La secuencia más completa de periódicos de nuestra hemeroteca corresponde a los periódicos La Unión (1901-1902), La Nueva Era (1904-1940), La Provincia (1935-1939) y La Calle (1979-1989). Editados en Viedma o Carmen de Patagones, La Nueva Era y La Provincia incluyen abundante información sobre el Territorio Nacional del Río Negro. Disponemos además de ejemplares de periódicos de las más variadas orientaciones como La Patagonia (1883), El Nene (1911), Flores del Campo (1916), etc.

\section{Archivo Fotográfico}

17 Este archivo contiene alrededor de 3.000 fotografías datadas entre fines de la década de 1860 y la de 1960. Allí se registran escenas familiares, personajes locales, eventos institucionales, mitines políticos y gremiales, procesiones religiosas, navegación fluvial y marítima, rurales, religión, patrimonio edilicio urbano, deportes y sociabilidad.

\section{Área de digitalización}

Al momento se encuentran digitalizados los periódicos La Unión y La Nueva Era, nuestro archivo fotográfico, los libros de bautismos, casamientos y defunciones de la Parroquia de Carmen de Patagones. También hemos iniciado la digitalización de los ejemplares posteriores a 1940 que integran el acervo del Archivo Histórico de la Provincia de Río Negro. En cuanto al Archivo Fotográfico ya hemos dado soporte electrónico a más de 1.800 placas. Finalmente, respecto de los libros parroquiales, hemos completado el $80 \%$ de la digitalización de los libros correspondientes al siglo XIX. 


\section{Atención de investigadores}

19 El horario de atención es de lunes a viernes de 8 a 13 y de 15 a 19 hs. Aunque puede prolongarse para el caso de los investigadores que nos visitan desde lejos. Si el proyecto es de interés para el museo, se ofrece la posibilidad de gestionar alojamiento gratuito. Con la investigación concluida y la copia de los resultados y publicaciones entregados al museo, se podrá contribuir a solventar gastos de pasajes hacia y desde Carmen de 
Patagones dentro del territorio nacional, reprografías y servicio de digitalización que se realizan en el Museo. 


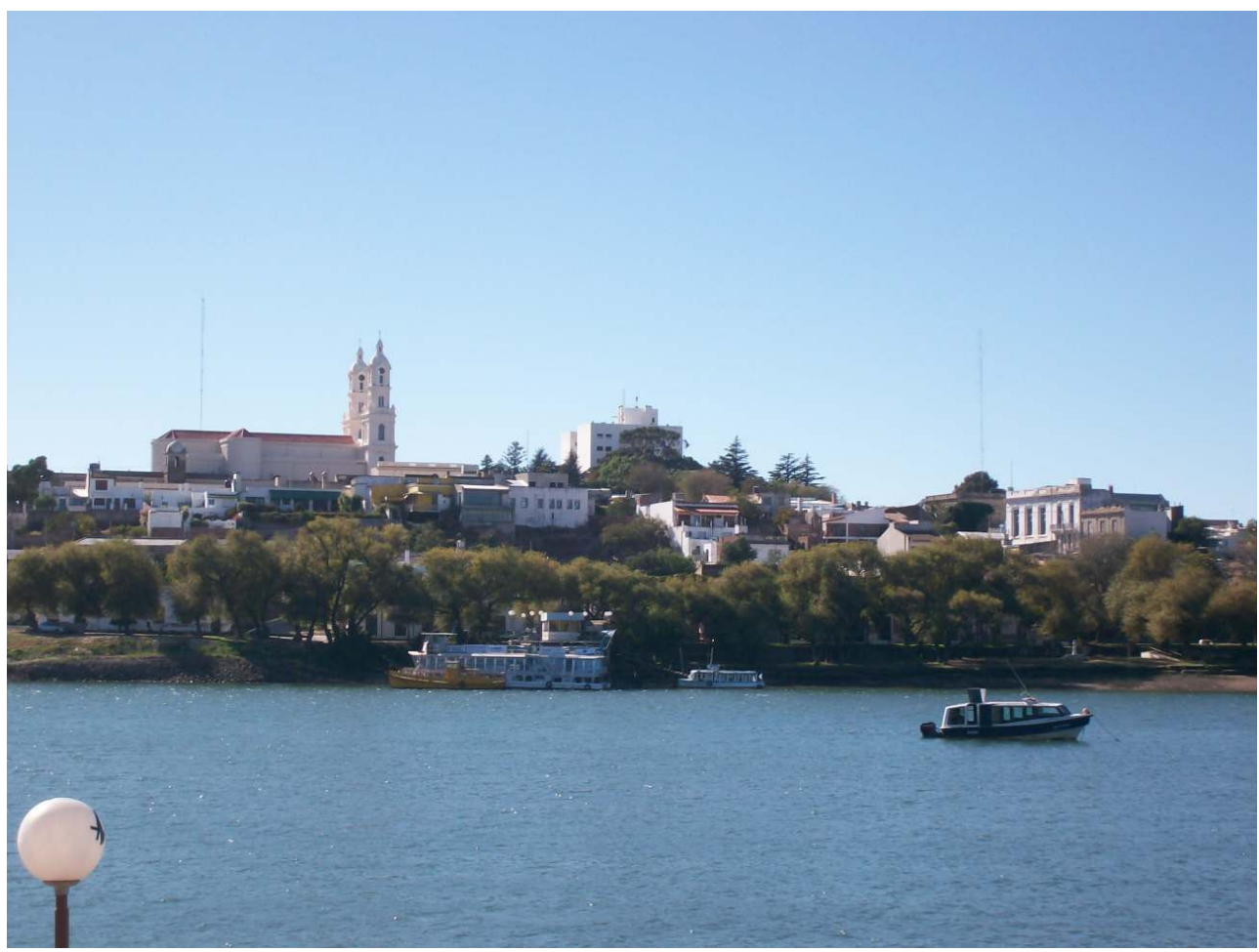

VISTA DE CARMEN DE PATAgONES DESDE LA MARgEN SUR DEL RÍo NEgRO.

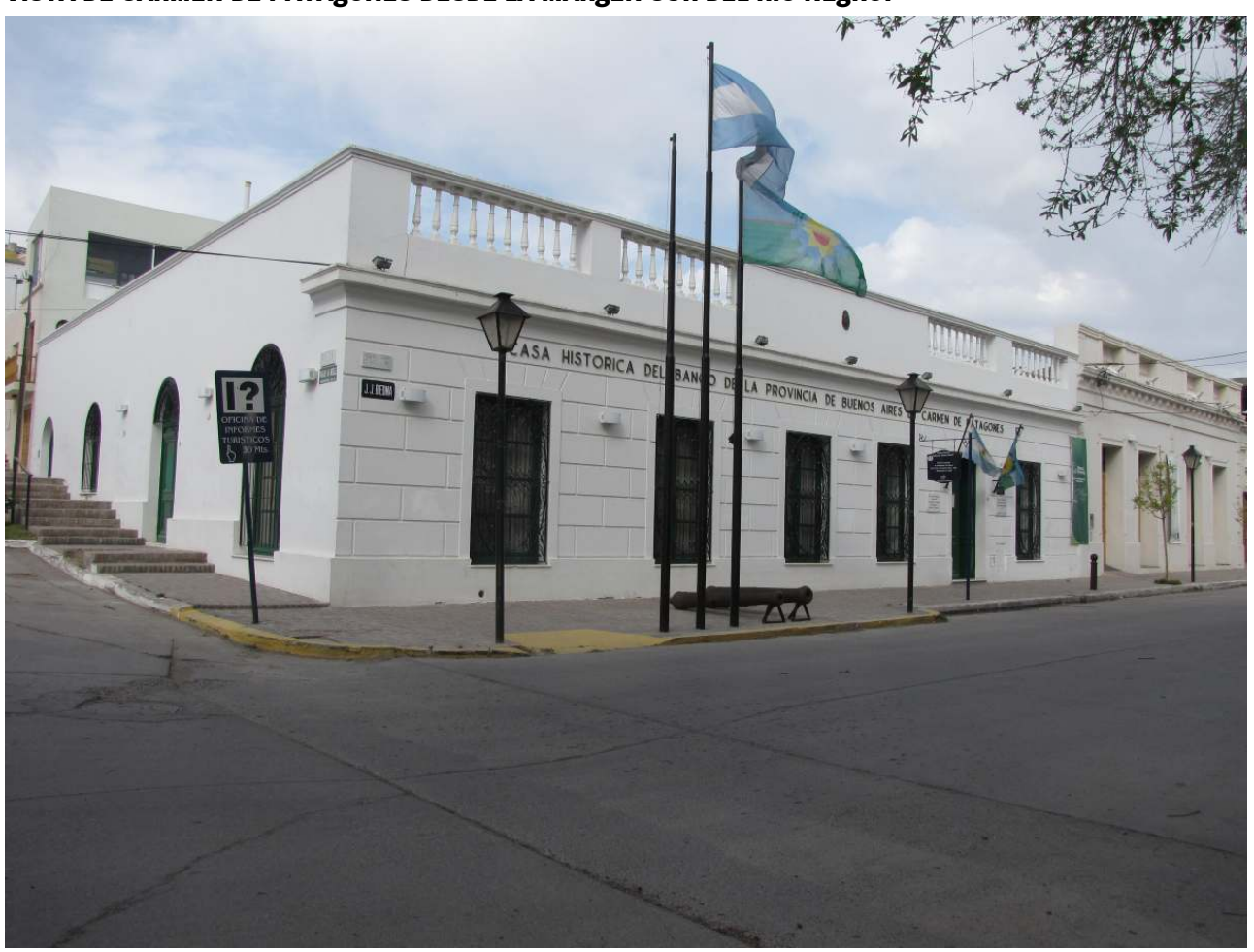

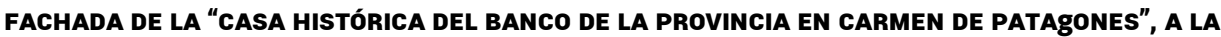
DERECHA, LA "CASA CAgLIERo". 


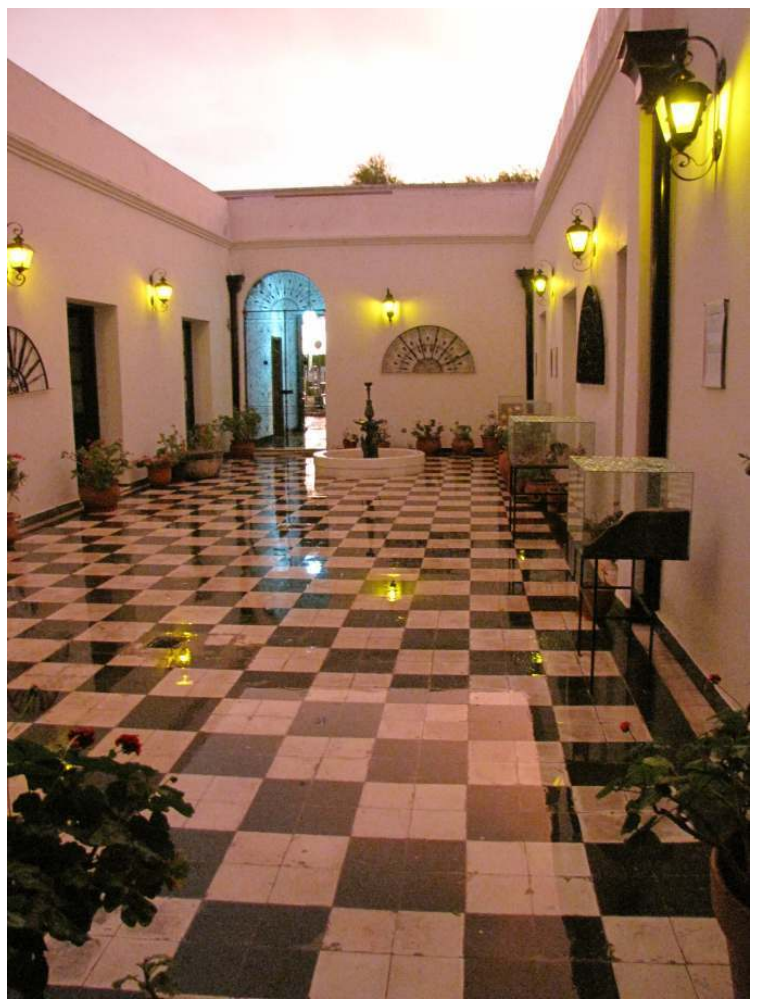

PATIO INTERIOR DEL MUSEO HISTÓRICO REgIONAL “EMMA NOZZı”.

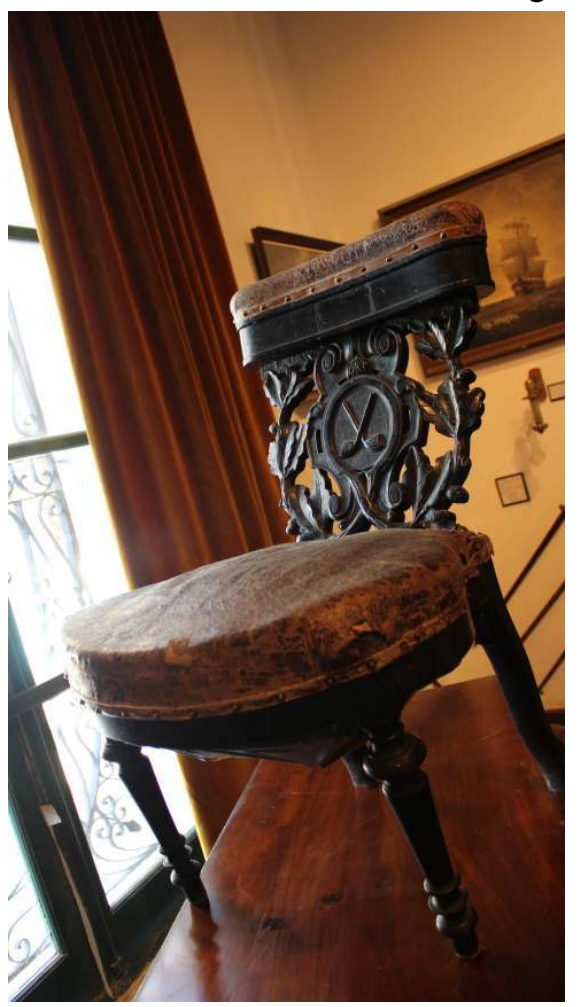

SILLA PARA FUMAR DEL CORSARIO FRANCÉS FRANCISCO FOURMANTIN DE DESTACADA ACTUACIÓN DURANTE LA gUERRA CON EL BRASIL. FUE COMANDANTE MILITAR DE CARMEN DE PATAgONES DURANTE LA DÉCADA DE 1850. 


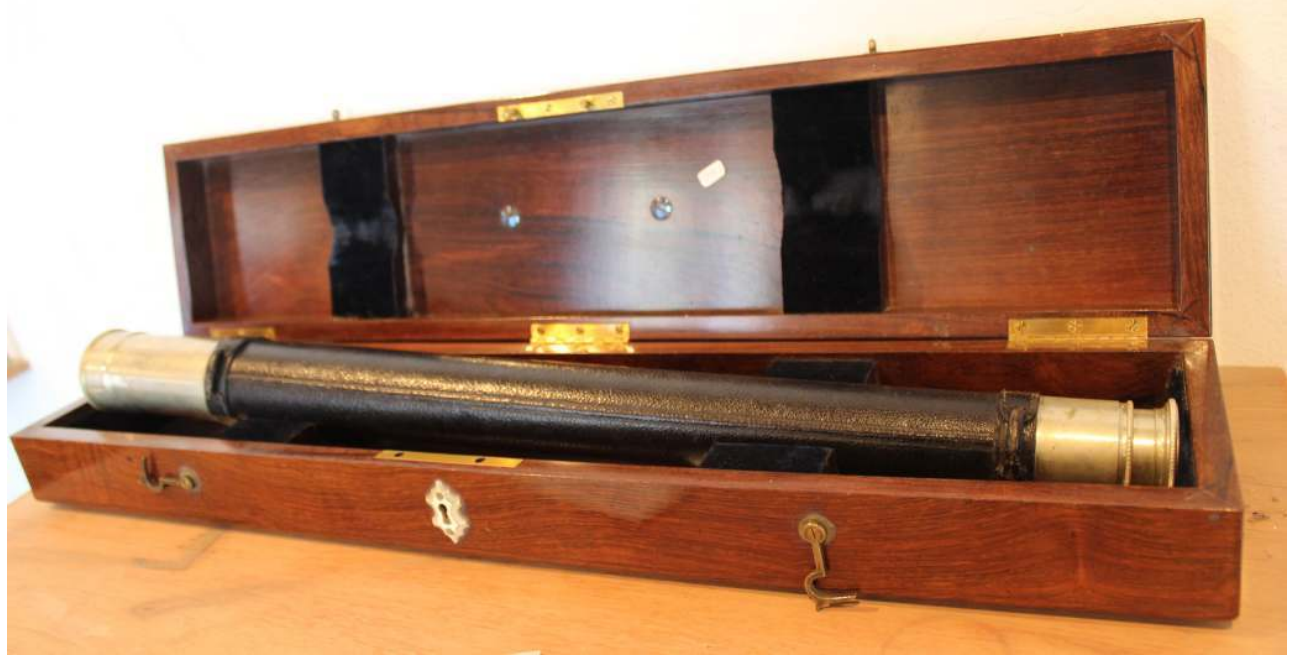

CATALEJO OBSEQUIADO POR EL EMPERAdOR ALEMÁN GUILLERMO I AL COMANDANTE PIEdRA BUENA POR RESCATAR A LA TRIPULACIÓN DEL “DR. HANSEN" EN 1874.

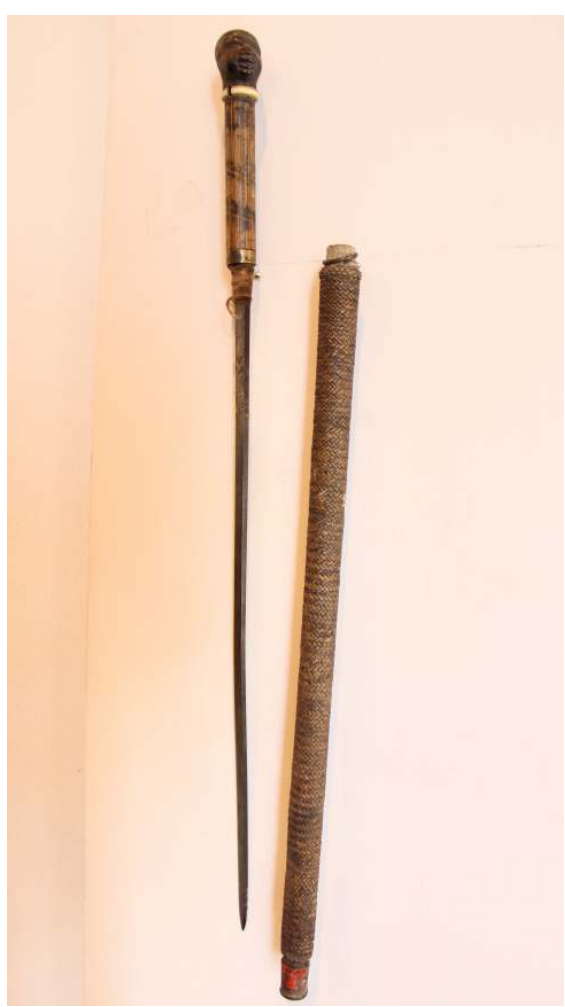

ESTOQUE PERTENECIENTE A UN ESCLAVO LIBERTO. LAS MUESCAS EN LA HOJA ENUMERAN LOS DUELOS EN QUE PARTICIPÓ. LAS MÁS PROFUNDAS INDICAN LOS MUERTOS Y LAS MÁS SUPERFICIALES A LOS HERIDOS. 


\section{ABSTRACTS}

The director of the Regional Historical Museum "Emma Nozzi" at Carmen de Patagones and his collaborator, both historians, tell the story of the institution, describe the building characteristics and its patrimony, summarizing salient aspects of the objects collections and archive. Services offered to researchers and the general public are detailed, along with the work of documentary recovery made in the museum.

El director del Museo Histórico Regional “Emma Nozzi” de Carmen de Patagones y su colaborador, ambos historiadores, narran la historia de la institución, presentan las características edilicias y el patrimonio de la misma, sintetizando los aspectos más salientes de las colecciones de objetos y archivo. Se detallan los servicios que se ofrecen a los investigadores y público en general, junto con la labor de rescate documental que realizan en el museo.

\section{INDEX}

Keywords: Keywords: archive, museum, heritage, regional history

Palabras claves: Palabras clave: archivo, museo, patrimonio, historia regional

\section{AUTHORS}

\section{LEONARDO A. DAM}

Museo Histórico Regional Emma Nozzi. Correo electrónico: museoema@live.com.ar 